\title{
Gestão Ambiental Empresarial: Estudo de Caso da Ferramenta de Teste de Estresse por Sequência
}

\author{
Corporativa de Gestión Ambiental: Estudio de caso de la Herramienta de \\ Prueba de Estrés para la Secuencia
}

\section{Corporate Environmental Management: Case Study of the Stress Test Tool by Sequence}

\author{
Isabella Regina Serra Brito Mesquita ${ }^{1}$ \\ Cícero Antônio Mesquita da Silva Brito \\ Isabel Cristina Vilela Guerra ${ }^{3}$
}

\begin{abstract}
Resumo
A consciência ambiental é uma tarefa precípua da sociedade humana. É imperativo aplicar uma abordagem multidisciplinar e atuar em todas as instâncias, público e privado, para desenvolver soluções sustentáveis. Nesta seara, o artigo busca estudar a gestão ambiental inserida na trajetória empresarial, tendo em vista que exerce influência nos resultados e na concorrência corporativa. Com relação às ferramentas de gestão ambiental, deu-se atenção à ferramenta de Teste de Estresse por Sequência, que foi criada com o objetivo de avaliar os eventuais riscos da seca.
\end{abstract}

Palavras-Chave: meio ambiente; gestão ambiental; sustentabilidade.

\section{Resumen}

La conciencia ambiental es una tarea precipua de la sociedad humana. Es imprescindible aplicar un enfoque multidisciplinario y actuar en todos los niveles, públicos y privados, para desarrollar soluciones sostenibles. En este campo, el artículo pretende estudiar la gestión ambiental insertada en la trayectoria empresarial, dado que ejerce influencia sobre los resultados y la competencia empresarial. Con respecto a las herramientas de gestión del medio ambiente, se prestó atención a la herramienta de Prueba de Estrés para la Secuencia, que fue creada con el fin de evaluar los posibles riesgos de sequía.

Palabras claves: medio ambiente; gestión del medio ambiente; la sostenibilidad.

1 Mestranda em Ambiente e Sociedade; Universidade Estadual de Goiás - UEG; Caldas Novas, Goiás, Brasil; isa_sb@hotmail.com.

2 Graduando em Administração; Universidade Metropolitana de Santos; Caldas Novas, Goiás, Brasil; cicero_mesquita@hotmail.com.

3 Mestranda em Ambiente e Sociedade; Universidade Estadual de Goiás - UEG; Caldas Novas, Goiás, Brasil; isabelcvguerra@gmail.com 


\begin{abstract}
Environmental awareness is a prime task of human society. It is imperative to apply a multidisciplinary approach and to act in all instances, public and private, to develop sustainable solutions. In this section, the article seeks to study the environmental management inserted in the entrepreneurial trajectory, considering that it exerts influence on results and corporate competition. Regarding the environmental management tools, attention was given to the Stress Test by Sequence tool, which was created with the objective of evaluating the possible drought risks.
\end{abstract}

Keywords: environment; environmental management; sustainability.

\title{
1. Introdução
}

A origem etimológica da palavra ambiente é o verbo latino ambio, ambire que significa "andar em volta ou entorno de alguma coisa". No Brasil foi consagrada a expressão meio ambiente, nos países que falam o castelhano, medio ambiente e no idioma francês e inglês, environnement e environment. De feitio que o termo meio ambiente compreende os meios biótico e abiótico que envolvem todas as formas de vida, de maneira a propiciar sua existência.

Deflui-se do art. $3^{\circ}$, I, da Lei n.6.938/81 o aspecto teleológico do conceito de meio ambiente ao expor que ele é "o conjunto de condições, leis, influências e interações de ordem física, química e biológica, que permite, abriga e rege a vida em todas as suas formas". Podese dizer, portanto, que o meio ambiente é um bem que deve ser protegido porque, em última análise, qualquer modificação ambiental desfavorável agride o equilíbrio ecológico e é considerada degradação (NASCIMENTO, 2006).

Dada a amplitude conceitual do meio ambiente, há que se considerar que a natureza é a base essencial para que a atividade humana mobilize o potencial produtivo da economia (SESI, 2013). Assim, sob a perspectiva econômica, a produção de bens e serviços que atendam às necessidades e aos desejos humanos envolve converter ou transformar os recursos naturais. Desse ponto de vista, há que se levar em conta a noção de esgotamento da biodiversidade.

O meio ambiente possui valor intrínseco, entretanto há que se admitir que ele deve ser usado para atender às necessidades humanas presentes e futuras. Sob este prisma, portanto, o sistema de produção e consumo deve respeitar as limitações ambientais, caso contrário, o uso perdulário dos recursos naturais poderá comprometer as funções ambientais e sociais.

Não é privilégio ou exclusividade do Poder Público conduzir a gestão ambiental, mas esta vocação é compartilhada com os segmentos organizados da sociedade e com os vários agentes empresariais. A bem ver, a todos incumbe proteger e buscar o equilíbrio ecológico. 
O desejo por retorno financeiro rápido, a falta de consciência ecológica e a baixa disposição por investimentos ambientais, associada a pressão por consumir são fatores que tem influenciado a sociedade empresarial e civil a gerir o meio ambiente com base no mínimo legalmente exigido. Esta visão elementar deve ser reavaliada, ora que não deve haver hostilidade entre o desenvolvimento econômico e o meio ambiente.

A boa experiência proporcionada pela ecossocieconomia oferece instrumentos para alicerçar a política ambiental e repensar a economia. A que se reconhecer que a expansão da economia deve ser em prol do bem-estar humano e a qualidade de vida, mas que estes elementos não estão apartados da sustentabilidade ecológica.

$\mathrm{O}$ artigo apoia-se na proposta de que a gestão ambiental empresarial decorre da eficiência econômica e do respeito ao meio ambiente, promovendo benefícios sociais.

\section{Objetivos}

Analisar a prática empresarial moderna, pautada não apenas no viés econômico, mas também no ecossocieconomia.

\section{Metodologia}

Frente ao paradigma da substituição do pensamento restrito ao perfil econômico para o ambiental e social, far-se-á por meio de uma abordagem interdisciplinar, uma pesquisa empírica com suporte teórico.

O ponto de partida para a pesquisa é a coleta de dados bibliográficos sobre a temática proposta, com vistas a ampliar o conhecimento sobre conceitos e métodos de investigação. Neste ponto, o foco foi coletar matérias genéricas e específicas a respeito do tema (LIMA, 2004).

Posteriormente, fez-se uso da pesquisa documental que "pressupõe o exame ou reexame de matérias que ainda não receberam qualquer tratamento analítico, no objetivo de fundamentar interpretações novas ou complementares” (LIMA, 2004, p.111). Para isso, buscou-se compreender o arranjo organizacional da "Ferramenta de Teste de Estresse por Sequência", como ferramenta estratégica da ecossocieoconomia. Desta forma, com base no material coletado será feita a interpretação dos dados. 


\title{
3. Resultados
}

Os padrões de consumo concomitante com os problemas ambientais têm exigido do Gestor ambiental uma nova concepção administrativa que contribua para ampliar a capacidade sustentável terrestre.

\begin{abstract}
A ameaça mais perigosa ao meio ambiente de nosso planeta talvez não seja representada pelas ameaças estratégicas propriamente ditas, mas por nossa percepção dessas ameaças, pois a maioria ainda não aceita o fato de que a crise que enfrentamos é extremamente grave. Naturalmente, sempre existe um certo grau de incerteza sobre assuntos complexos, e são necessários estudos cuidadosos, porém é muito fácil exagerar essas incertezas e estudar o problema em demasia - há quem faça exatamente isso -, a fim de evitar uma conclusão que incomoda. Contudo, existem pessoas que estão genuinamente preocupadas com o fato de que, embora saibamos muito a respeito da crise do meio ambiente, ainda há muito que desconhecemos (GORE, 2008, p. 45).
\end{abstract}

A problemática ambiental deve ser remetida ao mais elevado nível de consciência empresarial (VITERBO, 1998). Daí porque a competência da gestão ambiental não é exclusividade do Poder Público, mas requer uma participação da iniciativa privada.

Sob o aspecto institucional, relativo aos agentes que tomam as iniciativas de gestão, vale repisar não constituir privilégio ou exclusividade dos governos conduzir a administração do meio ambiente: os segmentos organizados da sociedade têm igualmente essa vocação. A recíproca também é verdadeira: a gestão ambiental não é apanágio da empresa, porque inerente também ao Poder Público. Entende-se, assim, que os vários agentes se complementam cada qual no seu âmbito de ação e com seus métodos próprios. (MILARÉ, 2011, p. 394)

As iniciativas para enfrentar os problemas ambientais têm propiciado acordos multilaterais entre os órgãos públicos e as empresas privadas. Nesse sentido, a Conferência de Estocolmo de 1972 contribuiu significativamente ao vincular o crescimento econômico com o meio ambiente. A partir daí surge a concepção de desenvolvimento sustentável.

A Comissão Mundial para o Meio Ambiente e Desenvolvimento (CMMAD), criada pela ONU em 1983, elaborou o relatório "Nosso futuro comum" que definiu desenvolvimento sustentável como aquele que atende às necessidades humanas da geração atual sem comprometer a possibilidade das gerações futuras de se sustentarem (BARBIERI, 2011).

O desenvolvimento sustentável exige da sociedade que suas necessidades sejam satisfeitas pelo aumento da produtividade e pela criação de oportunidades políticas, econômicas e sociais iguais para todos. Eles não devem pôr em risco a atmosfera, a água, o solo e os ecossistemas, fundamentais à vida na Terra. O desenvolvimento sustentável é um processo de mudança no qual o uso dos recursos, as políticas econômicas, a dinâmica populacional e as estruturas institucionais estão em harmonia e reforçam o potencial atual e futuro para o progresso humano (PENNA, 1999, p.140). 
Desta conceituação extrai-se, portanto, que o meio ambiente foi incluído no processo decisório da economia. A gestão ambiental passa a ser influenciada pela tríade governo, sociedade e mercado (Figura 1).

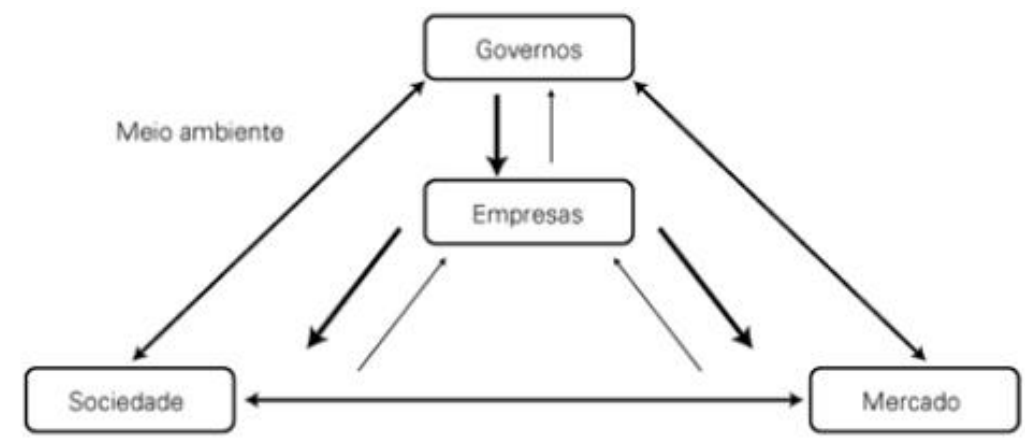

Figura 1. Gestão ambiental

Fonte: BARBIERI, 2011

Por seu turno, o artigo 225 da Constituição Federal Brasileira tutela o meio ambiente como responsabilidade comum e solidária do Poder Público e da coletividade, ou seja, o meio ambiente é patrimônio da coletividade. Outrossim, o êxito na gestão ambiental advém de ações solidárias e convergentes entre os entes público e privados.

A responsabilidade socioambiental deve ser preocupação basilar da empresa moderna, da sociedade civil e do Poder Público. O meio ambiente não configura uma ameaça ao desenvolvimento, mas a viabilidade econômica depende de se priorizar os fatores sociais e ambientais. Uma econômica baseada tão somente no lucro já está fracassada em sua origem. A era pós-moderna precisa despertar para suas responsabilidades ambientais que vão além do estritamente indispensável.

Em uma ponta dessa linha encontram-se as posições antropocêntricas extremadas, nas quais a natureza só tem valor enquanto instrumento dos seres humanos e estes possuem direitos absolutos sobre ela. A preocupação com o meio ambiente se dá na medida em que este se torna um problema para os humanos. Subjacente a essa postura está a concepção de um ser humano separado da natureza; essa dualidade lhe daria o direito de ser o seu senhor e de utilizá-la em seu benefício. Em termos gerais, os antropocêntricos mais extremados não se preocupam com a quantidade e a natureza da produção e do consumo, pois o importante é satisfazer as necessidades humanas, sejam elas essenciais ou não. A gestão ambiental de acordo com essa visão, caso exista, se restringe a seguir as legislações ambientais. A crença na capacidade da ciência e tecnologia de resolver os problemas ambientais legitima o uso abusivo do meio ambiente (BARBIERI, 2011, p.27-28).

Dentro desta perspectiva, a ecossocieconomia é essencial:

A ecossocioeconomia das organizações tem o desafio de resgatar princípios da integridade verdadeiramente humana, que podem ser sintetizados na valorização e preservação de tradições e relações sociais mais solidárias; na geração de trabalho e 
renda sob a perspectiva de modos de produção mais associativistas; no revigoramento dos significados de virtude humana e do próprio Estado, distanciados do racionalismo utilitarista; e na utilização apropriada dos recursos naturais e das capacidades humanas locais (SAMPAIO, 2005).

A ecossocioeconomia amplia o modo de pensar e analisar dos arranjos produtivos por transpor as barreiras da atividade econômica meramente utilitarista. Isto porque, o desenvolvimento tem muitas dimensões, dentre elas econômica, social e ambiental, e cada uma delas são interdependentes e complementares. Por isso é importante ter uma visão estratégica de decisões com ênfase na participação público-privada e incorporar demandas sociais locais. A ecossocioeconomia constrói-se com base no conhecimento transdisciplinar (SAMPAIO, 2005).

Além disso, a gestão democrática merece destaque na discussão sobre ecossocioeconomia, principalmente por meio da utilização do planejamento participativo (SAMPAIO, 2010).

Nessas condições, a ecossocioeconomia reconhece a ligação entre o meio ambiente e o desenvolvimento, ora que não existe opções excludentes. Ela possibilita pensar sob o prisma do ecodesenvolvimento e superar as limitações do utilitarismo econômico. $\mathrm{O}$ desenvolvimento qualitativo exige que os recursos naturais sejam utilizados com eficiência.

A empresa sustentável se preocupa em criar valor de longo prazo aos acionistas ou proprietários e contribuir para a solução dos problemas ambientais e sociais (BARBIERI, 2011). No plano internacional, uma importante iniciativa foi a criação do grupo "Iniciativa Financeira" (Uneo-FI), pelo Programa das Nações Unidas para o Meio Ambiente (Unep), com o objetivo de promover uma interação positiva entre o desenvolvimento econômico e social, e resguardar o meio ambiente.

Em 05 de abril de 2017 foi lançado um relatório intitulado "Testes de Estresse por Sequência - Tornar as Instituições Financeiras mais Resistentes aos Riscos Ambientais" financiado pelo Ministério Federal da Cooperação Econômica e Desenvolvimento (BMZ, em inglês) e pela Capital Natural (NCFA, em inglês), que apresentou a "Ferramenta de Teste de Estresse por Sequência" com o objetivo de auxiliar os bancos a avaliar se um cliente está vulnerável aos riscos da seca e como esta pode afetar um setor ou região.

A ferramenta em ação foca quatro cenários de seca, quais sejam Brasil, China, México e Estados Unidos da América. O teste de estresse em carteiras de empréstimos corporativos representa mais de US \$ 10 trilhões em ativos de oito instituições financeiras internacionais representadas por Caixa Econômica Federal (Brasil), Itaú Unibanco (Brasil), Santander 
(Brasil), Banorte (México), Citibananamex (México), Fundos de Desenvolvimento Rural FIRA (México), Citigroup (EUA), UBS Banco Industrial e Comercial da China (ICBC).

O relatório destaca que as secas extremas impactam em 10 (dez) vezes o descumprimento dos acordos econômicos. Além de afetar principalmente os setores de abastecimento de água, a agricultura e a produção de energia elétrica. Neste sentido, por meio da ferramenta há uma sinalização de promover a gestão de risco ambiental entre setor privado, governo e sociedade empresária.

A abordagem estratégica ambiental promove práticas de prevenção e desenvolvimento econômico. Neste ponto, a nova ferramenta desenvolvida pressupõe uma nova relação entre a empresa e o consumidor para reduzir os impactos ambientais negativos.

\section{Conclusões}

O desenvolvimento econômico é uma necessidade. Entretanto, ele tem limites estabelecidos pela disponibilidade dos recursos naturais, isto porque é o meio ambiente que fornece matéria prima. O panorama ambiental exige ações coordenadas em prol da sustentabilidade.

Cuidar do meio ambiente é dever e responsabilidade de todos. Com os avanços tecnológicos, que principalmente aumentam a produtividade das empresas, cada vez mais se deve aguçar o interesse pelo tema, pois a exploração desse bem precioso e esgotável também se acelera.

A gestão ambiental empresarial é possível, todavia é necessária uma atuação conjunta para promover desenvolvimento financeiro de maneira sustentável. Isto porque todos se valem de recursos naturais finitos. O sucesso desse roteiro depende do aperfeiçoamento da consciência ambiental.

Por outro lado, há ganhos econômicos, ambientais e sociais com a adoção da gestão ambiental empresarial. Esta visão sistêmica foi adotada na produção da ferramenta de Teste de Estresse por Sequência, a qual levou em conta o risco ambiental e seus desdobramentos.

Portanto, por meio de uma atuação efetiva na modelagem ambiental os ganhos corporativos são alcançados, que incluem a otimização dos processos de produção e até mesmo melhoria da imagem institucional. 


\section{Referências}

BARBIERI, José Carlos. Gestão ambiental empresarial: conceitos, modelos e instrumentos. 3. ed. São Paulo: Saraiva, 2011.

BRASIL. Constituição da República Federativa do Brasil (1988). Brasília, DF: Senado Federal. Diário Oficial da União, 05.10.1988.

BRASIL. Lei nº.938, de 31 de agosto de 1981. Dispõe sobre a Política Nacional do Meio Ambiente, seus fins e mecanismos de formulação e aplicação, e dá outras providências. Brasília, DF: Senado Federal. Diário Oficial da União, 2.9.1981.

GORE, Al. A terra em balanço: ecologia e o espírito humano. 2. ed. São Paulo: Gaia, 2008.

HADDAD, Paulo Roberto. Meio ambiente, planejamento e desenvolvimento sustentável. São Paulo: Saraiva, 2015.

LIMA, Manolita. Monografia a engenharia da produção acadêmica. São Paulo: Saraiva, 2004.

MILARÉ, Édis. Direito do ambiente. 7. ed. São Paulo: Revista dos Tribunais, 2011.

NASCIMENTO, Elimar Pinheiro do; VIANA, João Nildo Souza. Economia, meio ambiente e comunicação. Rio de Janeiro: Garamond, 2006.

PENNA, Carlos Gabaglia. O estado do Planeta: sociedade de consumo e degradação ambiental. Rio de Janeiro: Record, 1999.

Programa das Nações Unidas para o Meio Ambiente - Iniciativa Financeira (UNEP FI). Testes de Estresse por Sequência - Tornar as Instituições Financeiras mais Resistentes aos Riscos Ambientais. Disponível em:

$<$ http://www.unepfi.org/news/themes/ecosystems/innovative-new-tool-helps-banksunderstand-risk-of-loan-default-caused-by-drought/>. Acesso em: 06/04/2017.

SAMPAIO, Carlos Alberto Cioce. Turismo como fenômeno urbano: princípios para se pensar a ecossocioeconomia. Santa Cruz do Sul, SC: Edunisc, 2005.

SAMPAIO, Carlos Alberto Cioce. Gestão que privilegia uma outra economia: ecossocioeconomia nas organizações. Blumenau: Edifurb, 2010.

SESI - Serviço Social da Indústria. Conteúdos básicos comuns. Departamento Nacional. Brasília: SESI/DN, 2013. 
RELACult - Revista Latino-Americana de Estudos em Cultura e Sociedade

Revista Latinoamericana de Estudios en Cultura y Sociedad | Latin American Journal of Studies in Culture and Society V. 03, ed. especial, dez., 2017, artigo no 491| relacult.claec.org | e-ISSN: 2525-7870

VITERBO JUNIOR, ÊNIO. Sistema integrado de gestão ambiental: como implementar um sistema de gestão que atenda à norma ISSO 14001, a partir de um sistema baseado na norma ISSO 9000. São Paulo: Aquariana, 1998. 